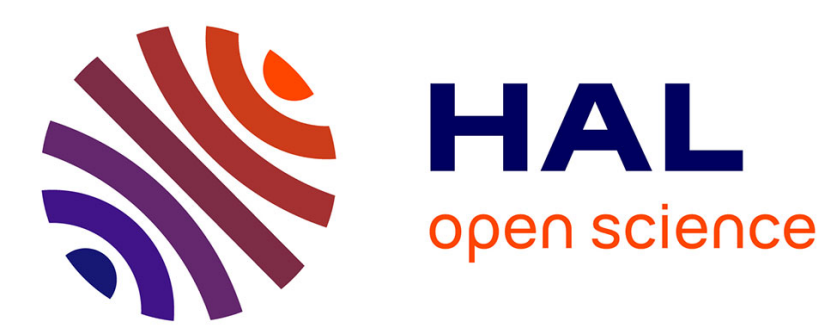

\title{
Death and illness in the media
}

James Matthew Lloyd Williamson, Charlotte Skinner, David Hocken

\section{To cite this version:}

James Matthew Lloyd Williamson, Charlotte Skinner, David Hocken. Death and illness in the media. International Journal of Clinical Practice, 2011, 65 (5), pp.547. 10.1111/j.1742-1241.2011.02658.x . hal-00631700

\section{HAL Id: hal-00631700 \\ https://hal.science/hal-00631700}

Submitted on 13 Oct 2011

HAL is a multi-disciplinary open access archive for the deposit and dissemination of scientific research documents, whether they are published or not. The documents may come from teaching and research institutions in France or abroad, or from public or private research centers.
L'archive ouverte pluridisciplinaire HAL, est destinée au dépôt et à la diffusion de documents scientifiques de niveau recherche, publiés ou non, émanant des établissements d'enseignement et de recherche français ou étrangers, des laboratoires publics ou privés. 


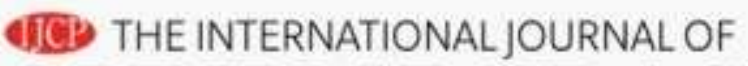 \\ CLINICAL PRACTICE}

\section{Death and illness in the media}

\begin{tabular}{|c|c|}
\hline Journal: & International Journal of Clinical Practice \\
\hline Manuscript ID: & IJCP-01-11-0029.R1 \\
\hline Wiley - Manuscript type: & Original Paper \\
\hline $\begin{array}{r}\text { Date Submitted by the } \\
\text { Author: }\end{array}$ & 06-Feb-2011 \\
\hline Complete List of Authors: & $\begin{array}{l}\text { Williamson, James; The Great Western Hospital, General Surgery } \\
\text { Skinner, Charlotte; Oxford University, Oxford Medical School } \\
\text { Hocken, David }\end{array}$ \\
\hline Specialty area: & \\
\hline
\end{tabular}

\section{SCHOLARONE" \\ Manuscripts}




\section{Title Page}

Title: Death and IIIness in the media

Authors: JML Williamson ${ }^{1}$, CI Skinner ${ }^{2}$, DB Hocken ${ }^{1}$

Institutions:

1: Department of General Surgery, The Great Western Hospital, Marlborough road, Swindon, SN3 6BB. Tel: 01793 604020, Fax: 01793646204

2: Oxford Medical School, Medical Sciences Office, John Radcliffe Hospital, Oxford, OX3 9DU

Authors email: jmlw@doctors.org.uk 


\begin{abstract}
Introduction

The media may affect how illness is perceived, in terms of its prevalence, severity and outcomes. The media also influences our perception of death and leads to an over-estimation of incidence of some causes of mortality. Articles depicting medical subjects may not be in-depth and are often influenced by non-medical issues. The media has both a positive impact on the population, in providing opportunistic health information, and a negative impact, causing an over-estimation of severity and incidence of certain diseases. This article aims to assess if media reporting of illness and death represents national statistics.
\end{abstract}

\title{
Method
}

The 10 most common daily read UK newspapers were assessed for articles relating to the most common causes of UK mortality. The searches were performed via each newspaper's online search facility over a 12-month period. Where appropriate, media friendly terms were used as search terms.

\section{Results}

18,482 pertinent articles were found relating to the most common causes of death in the UK. When the reportage of illness was compared to the actual incidence Cerebrovascular accidents and Chronic obstructive pulmonary disease were underrepresented in the media, with ratios 0.31 and 0.01 to 1 respectively. Flu/pneumonia, prostate cancer, dementia and breast cancer all have a large media profile, with ratios of $5.52,3.06,4.09$ and 4.9 to 1 respectively. 


\section{Conclusion}

The media has a significant impact on our perceptions of illness and death. This may influence how patients seek medical attention and their concerns at consultation. Strategies to improve the educational content of the media may enhance the dissemination of health information via this resource.

\section{What's already known about this topic?}

The media is known to greatly impact on the public's understanding and perception of death and illness. Estimations of causes of death by the public often bear little relation to official statistics, but do correlate with the frequency of print media reporting. Previous research has shown that certain cancers are under- or overrepresented in the press and on the internet, but little is known about the representation of common causes of mortality.

\section{What does this article add?}

This article highlights the discrepancy between actual incidence and media coverage of certain causes of death. Over-represented diseases may be considered to be more serious and pose more of a threat than equally serious under-represented infectious diseases. This disproportionate media exposure may affect patients' concerns when seeking consultation. 


\section{Introduction}

The media is considered to be the most important source of health information for the general public [1-2]. The media decides on what issues to present to the population and the level of importance attached to them, influencing public understanding and awareness of disease [3]. Therefore, the media may affect how illness is perceived, in terms of its prevalence, severity and outcomes [1-2,4-7]. In terms of what is reported by the print media, articles tend to be on subjects that are prevalent, relevant and of interest to the public [5]. Articles depicting medical subjects may not be in-depth and are often influenced by non-medical issues, such as celebrity status or significant public events [2-3,5,8-9]. Thus there may be a discrepancy in the reportage of illness compared to prevalence of actual disease [12]. The media also influences our perception of death and, in particular, leads to an over-estimation of incidence of some causes of mortality [1,7]. Estimations of causes of death by the public often bear little relation to official statistics, but do correlate with the frequency of print media reporting [10-11]. This observation manifests itself as an underestimation of the incidence of common causes of death and an overestimation or rarer causes [11]. Previous work into the investigation of print media reporting has noted both a poor relationship between the frequency of reporting deaths and mortality rates [11-12].

The passive nature of information dissemination coupled with easily understandable articles (unlike many patient information leaflets) may be a key factor in raising the overall awareness of disease by the media [1-3,5,8,13-14]. This opportunistic provision of health information is in addition to advertisements from both government 
The aims of this paper are to assess the reportage of the 10 most common causes of death in the UK by the 10 most read daily newspapers and to compare the frequency of mortality in the print media compared to incidence of disease.

funded institutions and charitable organisations. Moreover, policies of media advocacy, which entail the deliberate use by groups to advance specific causes or concerns, may influence disease coverage [5,14]. Focused media advertising strategies on a particular disease have been shown to increase public awareness of that disease and improve patient knowledge [14]. However, the media reportage of illness can induce negative health consequences $[6,15]$. Media exposure is a strong predictor of posttraumatic stress syndrome and stress reactions after significant events, even in populations not directly affected (e.g. after the September $11^{\text {th }}$ attack in New York) [16-18]. Moreover, certain events trigger amplification in perceived risk which is not ultimately accompanied by a commensurate risk increase (e.g. Chernobyl Disaster [19], cancer risk from cell phones [20], and anthrax outbreaks [21]). 


\section{Method}

The top 10 most read daily UK newspapers (The Sun, Daily Mail, The Mirror, The Telegraph, The Times, Daily Express, Daily Star, The Guardian, The Independent and the Financial Times) were assessed for articles relating to the 10 most common causes of death in the UK over a 12-month period $\left(1^{\text {st }}\right.$ January $2009-31^{\text {st }}$ December 2009) [22]. The combined estimated daily circulation of these newspapers is 25.3 million, i.e. $41 \%$ UK population [22-23]. The most common causes of death were obtained from the Office for National Statistics and are shown in table 1 [24]. The searches were performed via each newspaper's online search facility and 'media friendly' terms were used. Where the cause of death was well known to the population, e.g. "breast cancer", the search term was the same as the cause of death. When the cause of death was unfamiliar, e.g. "ischaemic heart disease", then several terms were used (e.g. heart disease, heart attack, cardiac arrest). Only the term yielding the most number of relevant articles was recorded, so as not to duplicate any searches. Table 2 shows the mesh terms used for the searches. Analysis of the exact content of each article was not possible given the scope of the search.

\begin{tabular}{lr} 
Cause of Death & \% of all Deaths \\
\hline Ischaemic Heart Disease & $18.50 \%$ \\
Cerebrovascular Disease & $10.70 \%$ \\
Flu/Pneumonia & $6.40 \%$ \\
Cancer of trachea, bronchus, lung & $5.30 \%$ \\
Chronic Obstructive Pulmonary Disease (COPD) & $5.20 \%$ \\
Dementia and Alzheimer's Disease & $3.40 \%$ \\
Colorectal Cancer & $2.60 \%$ \\
Breast Cancer & $2.10 \%$ \\
Prostate Cancer & $1.70 \%$
\end{tabular}


Heart Failure $\quad 1.60 \%$

Table 1: The incidence of the most common causes of death in the UK [24]

\section{Cause of Death}

Ischaemic Heart Disease

Cerebrovascular Disease

Flu/Pneumonia

Respiratory cancer

(trachea, bronchus, lung)

Chronic obstructive pulmonary disease (COPD)

Dementia and Alzheimer's

Colorectal cancer

Breast cancer

Prostate cancer

Heart failure
Search terms used

Heart Attack

Coronary Heart Disease

Cardiac Arrest

Stroke

Influenza

Flu

Pneumonia

Throat cancer

Lung cancer

COPD

Chronic obstructive pulmonary disease

Chronic emphysema

Chronic bronchitis

Dementia

Alzheimer's Disease

Bowel cancer

Colon cancer

Sigmoid cancer

Rectal cancer

Anal cancer

Colorectal cancer

Breast cancer

Prostate cancer

Heart failure 


\section{Results}

Of the 21,561 articles identified over 12 months, refining of the search terms yielded 18,482 pertinent articles covering the most common causes of death in the UK (table 1). The most commonly reported conditions were Flu/pneumonia (6525 articles, $35.2 \%$ of total), ischaemic heart disease (3849 articles, $20.8 \%$ ) and dementia (2577 articles, $13.9 \%$ ). The least number of articles related to Chronic Obstructive Pulmonary Disease (COPD) (95 articles, $0.5 \%$ of total) and heart failure (547 articles, 3\%). The full results are displayed in table 3 along with the ratio of articles: deaths (the prevalence of disease in the media). When the numbers of articles are compared to the number of deaths, the media profile of each illness can be seen (figure 1). This media profile shows a ratio of number of articles to the incidence of disease, and represents the over- or under-representation of each illness. A ratio of 1 would indicate the expected number of articles compared with the incidence of death; any number above this indicates and over-representation, while ratios of less than one indicate under-representation by the media. The notable under-represented diseases are Cerebrovascular accidents (CVAs) and COPD, with ratios 0.31 and 0.01 respectively. In terms of over-representation, Flu/pneumonia, prostate cancer, Dementia and Breast Cancer all have a large media profile, with ratios of $5.52,3.06$, 4.09 and 4.9 respectively. 


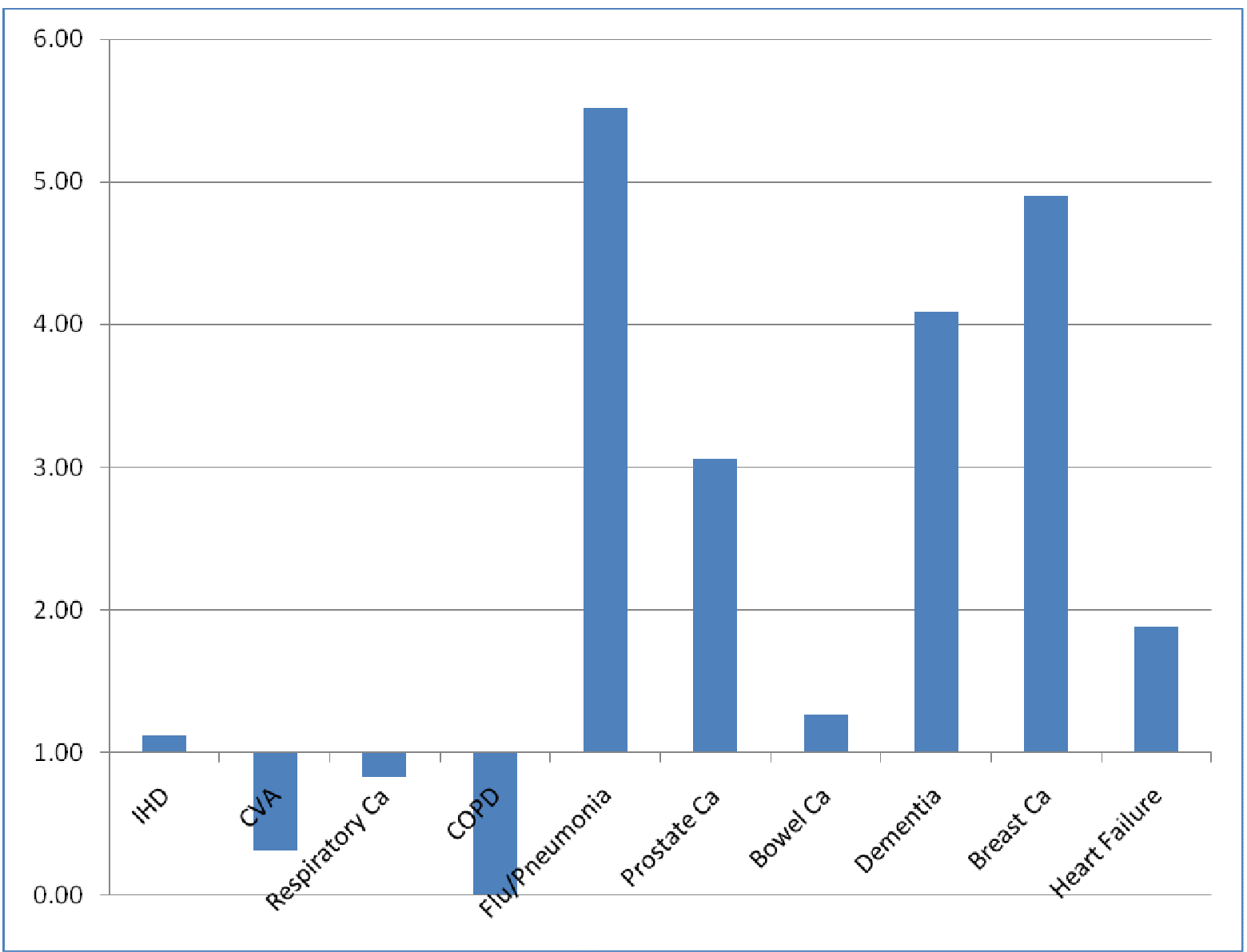

Figure 1: The relevant prevalence of disease in the media compared with actual incidence, i.e. the media profile $(\mathrm{IHD}=$ Ischemic heart disease, CVA = Cerebrovascular accident, COPD = Chronic Obstructive Pulmonary Disease, $\mathrm{Ca}=$ Cancer)

\begin{tabular}{lrrr}
\hline Disease & Number of articles & Percentage of total & \multicolumn{2}{c}{ Media profile } \\
\hline Ischemic heart disease & 3849 & 20.8 & 1.12 \\
Cerebrovascular accident & 605 & 3.3 & 0.31 \\
Respiratory cancer & 814 & 4.4 & 0.83 \\
Chronic Obstructive & 95 & 0.51 & 0.01 \\
Pulmonary Disease & 6525 & 35.3 & 5.52 \\
Flu/Pneumonia & 966 & 5.2 & 3.06 \\
Prostate cancer & 603 & 3.3 & 1.27 \\
Bowel cancer & & & \\
\hline
\end{tabular}




\begin{tabular}{lcrr}
\hline Dementia & 2577 & 13.9 & 4.09 \\
Breast cancer & 1901 & 10.3 & 4.9 \\
Heart Failure & 547 & 3 & 1.88 \\
\hline
\end{tabular}

Table 3: Number of articles related to each search term. There media profile is the ratio of articles: deaths) 


\section{Discussion}

The media does not exist as a health promotion platform, but it can influence how illness is perceived, in terms of its prevalence, severity and outcomes [1-7]. The media play a critical role in shaping public opinion regarding issues, including infectious disease, illness and death [6]. The media is regarded as one of the most important sources of patient information, potentially because it is easily accessible and the public is exposed to it passively $[2-3,14,25]$. The media functions as an interface between the scientific community, government, and the public [26-27]; it therefore has a responsibility to strike a careful balance between raising awareness of issues of public concern and irrationally alarming the public at large $[1,26]$. The reportage on health issues is not regulated by any medical representatives, but rather on what is deemed 'newsworthy' - issues that are rare, novel and dramatic rather than those of higher relative risk $[1,27]$. Since alarming content is more common in newscasts than reassuring or neutral content [28], and an estimated $11 \%$ of news articles include exaggerated claims [29], the possible impacts of disease being frequently presented in the media deserves attention.

Our results have shown that there is a discrepancy between the number of articles on certain diseases and their associated prevalence. Flu/pneumonia, prostate cancer, Dementia and Breast Cancer are all over-expressed by the print media. Potential reasons for this include the 'Swine flu' outbreak and coverage of the Libyan Lockerbie bomber, Mr Al-Meghari (accounting for flu/pneumonia and prostate cancer respectively). Despite this topical rise in coverage, there seems to be a genuine over-expression of dementia and breast cancer articles. This increased reporting 
may be secondary to charity works to promote their respective illnesses (e.g. breast cancer fun runs) and celebrity coverage (e.g. Kylie Minogue for breast cancer and Terry Pratchett for Alzheimer's disease). For under-reported diseases, there seems to be a genuine lack of articles on CVAs and COPD (the second and fourth largest causes of mortality in the UK). Some medical phrases may be edited out by newspapers to improve the comprehension of any article to the lay public [9]. This could prove an issue in monitoring how some diseases are recorded by the print media, but our study has tried to minimise this effect by using lay terms where appropriate.

Given the vast number of search results, it was not possible to record the actual content of the newspaper articles. As these search terms could appear anywhere in each article we cannot comment on the accuracy or information content within them. This study primarily aims to assess the number of articles on each condition and to assess if this accurately reflects incidence of disease. We accept that while the media has some discrepancy on what news issues it reports, coverage is greatly influenced by what 'newsworthy' events are occurring. Despite these limitations, we feel that these results are accurate and are worthy of comment.

Our results suggest two main areas of concern. Firstly, diseases with a high media profile may be considered to be more serious and pose more of a threat than equally serious under-represented infectious diseases. Diseases that are frequently covered by the media are not, however, considered to be 'worse' than those not covered in the media [6]. Disproportionate media exposure may have effects on perceptions of 
disease other than estimates of prevalence, such as disease severity, and whether something is a disease at all $[6,10-11]$. If increased media frequency can in fact alter perceptions of disease, then this has implications for many aspects of health decision making and, potentially, government funding. Secondly, patients with low media profile diseases may feel stigmatised or isolated as a result of their condition $[2,29]$. The media should be an ideal modality to break down taboos and stigma, potentially by focusing on the 'human element' of disease [2,29].

The scope for utilising the media to improve patient education should not be underestimated. Highlighting symptoms of the disease may encourage patients to seek medical consultation at an earlier stage, which could improve outcomes and survival. This is particularly pertinent in cancers as patients are known to be symptomatic for some time prior to presentation [2,31]. An active policy of media advocacy (collaboration between health care professionals and journalists) could result in articles that are relevant to the population, informative and in a style and format that is easily comprehendible to the lay public [2,25]. Professional bodies, such as the Department of Health, the NHS, the Royal Colleges or the Royal Society of Medicine could release articles or information directly to newspapers. This may improve the quality of relevant medical information provided in newspaper articles. An additional method to enhance the educational content of these articles could focus on targeted advertising - information about the disease in the article could be provided separately and give links to further information sources. This advertising box could be funded by relevant charities. 


\section{Conclusion}

The media has a significant impact on our perceptions of illness and death. Articles can have a positive impact, by acting as a source of health information and breaking down the stigma of disease. However, media coverage may also have a negative impact, with diseases with a high media profile being considered more prevalent and more serious than they are.

As clinicians we need to be aware of the impact that media coverage has on illness for the general population. This may influence how patients seek medical attention and their concerns at consultation. Patients may have a background understanding of their disease (or perceived illness) from the health information provided by the media. In this age of television and internet media it is important to consider the impact of media reporting on public perception of disease, and public health in general. Strategies to improve the educational content of the media may enhance the dissemination of health information via this resource. 


\section{References}

1: The PLoS Medicine editors. False hopes, unwarranted fears: The trouble with medical news stories. PLoS Medicine 2008;5:681-683

2: Williamson JML, Jones $\mathrm{IH}$, Hocken DB. How does the media profile of cancer compare with prevalence? Annals of the Royal College of Surgeons of England 2011;93:9-12

3: Schwitzer G, Mudur G, Henry D, Wilson A, Goozner M, Simbra M, Sweet M, Baverstock KA. What are the roles and responsibilites of the media in disseminating health information. PLoS Medicine 2005;2:576-582

4: Mazur A, Lee J. Sounding the global alarm: Environmental issues in the US National News. Social Studies Science 1993;23:681-720

5: HD Holder, AJ Treno. Media advocacy in community prevention: news as a means to advance policy change. Addiction 1997;92:S1 89-99

6: Young ME, Geoffrey RN, Humphries KR. Medicine in the popular press: the influence of media on perceptions of disease. PLoS One 2008;3: e3552

7: Frewer LJ, Miles S, Marsh R. The media and genetically modified foods: evidence in support of social amplification of risk. Risk Anal 2002;22:701-711

8: Chapman S, McLeod K, Wakefield M, holding S. Impact of celebrity illness on breast cancer screening: Kylie Minogue's breast cancer diagnosis. MJA 2005;183(5):247-250

9: Williamson JML, Hocken DB. Pancreatic cancer in the media: the Swayze shift. The Annals of the Royal College of Surgeons of England. 2010;92:537-8.

10: Coombs B, Slovic P. Newspaper coverage of causes of death. J Quarterly 1979;56: 837-843 
11: Frost K, Frank E, Maibach E. Relative risk in the news media: a quantification of misrepresentation. Am J of Pub Health 1997;87:842-845

12: Kristiansen CM. Newspaper coverage of diseases and actual mortality statistics. Eur J Soc Psych 1983;13:193-94.

13: Williamson JML and Martin AG. Analysis of patient information leaflets provided by a district general hospital by the Flesch and Flesch-Kincaid method. International Journal of Clinical Practice 2010;64:1824-1831

14: R Durrant, M Wakefield, K McLeod, K Clegg-Smith, S Chapman. Tobacco in the news: an analysis of newspaper coverage of tobacco issues in Australia, 2001. Tobacco control 2003;12:ii75-ii81

15: Dyer O. Disease awareness campaigns turns healthy people into patients. British Medical Journal 2006;332:871

16: Vasterman P, Yzermans CJ, Dirkzwager AJ. The role of the media and media hypes in the aftermath of disasters. Epidemiol Rev 2005;27:107-114

17: Galea S, Resnick H. Posttraumatic stress disorder in the general population after mass terrorist incidents: Considerations about the nature of exposure. CNS Spectrums 2005;10:107-115

18: Schuster MA, Stein BD, Jaycox LH, Collins RL, Marshall GN, et al. (2001) A national survey of stress reactions after the September 11, 2001, terrorist attacks. New Engl J Med 2001;345:1507-1512

19: Valeska S (2005) Chernobyl: poverty and stress pose bigger threat than radiation. Nature 2005;437:181 
20: Moulder JE, Erdreich LS, Malyapa RS, Merritt J, Pickard WF, Vijayalaxmi. Cell phones and cancer: what is the evidence for a connection? Rad research $1999 ; 151: 513-531$

21: Dougall AL, Hayward MC, Baum A. Media exposure to bioterrorism: Stress and the anthrax attacks. Psychiatry 2005;68:28-42

22: National Readership Survey. NRS readership estimates - Newspapers and supplements. $\quad$ October 2008-September 2009. http://www.nrs.co.uk/toplinereadership.html (accessed November 2009)

23: Office for National Statistics. Press release: UK population grows to 61.4 million. www.statistics.gov (downloaded September 2009)

24: Griffiths C, Rooney C, Brock A. Leading causes of death in England and Wales how should we group causes. Office for National Statistics. Health Statistics Quarterly 28; Winter 2005.

25: Williamson J, Hocken D. How much vascular disease is reported by the UK media? International Journal of Clinical Practice 2010;64:1167-1168

26: Cooper CP, Roter DL. "If It Bleeds It Leads"? Attributes of TV health news stories that drive viewer attention. Publ Health Rep 2000;115:331-338.

27: Sun A, Zhan J, Tsoh J, Wong-Kim E, Chow E. The effectiveness in utilizing Chinese media to promote breast health among Chinese women. Journal of Health Communication 2007;12:157-171

28: Fischhoff B, Bostrom A, Quadrel MJ. Risk perception and communication. Annu Rev Publ Health 1993;14:183-203 
29: Frick U, Rehm J, Eichhammer P. Risk perception, somatization, and self report of complaints related to electromagnetic fields-a randomized survey study. Int $J$ Hyg Environ Health 2002;205:353-360

30: Link BG, Phelan JC. Stigma and its public perceptions. Lancet 2006;367:528-29

31: Macleod U, Mitchell ED, Burgess C, Macdonald S, Ramirez AJ. Risk factors for delayed presentation and referral of symptomatic cancer: evidence for common cancers. British Journal of Cancer 2009;101:S92-101 


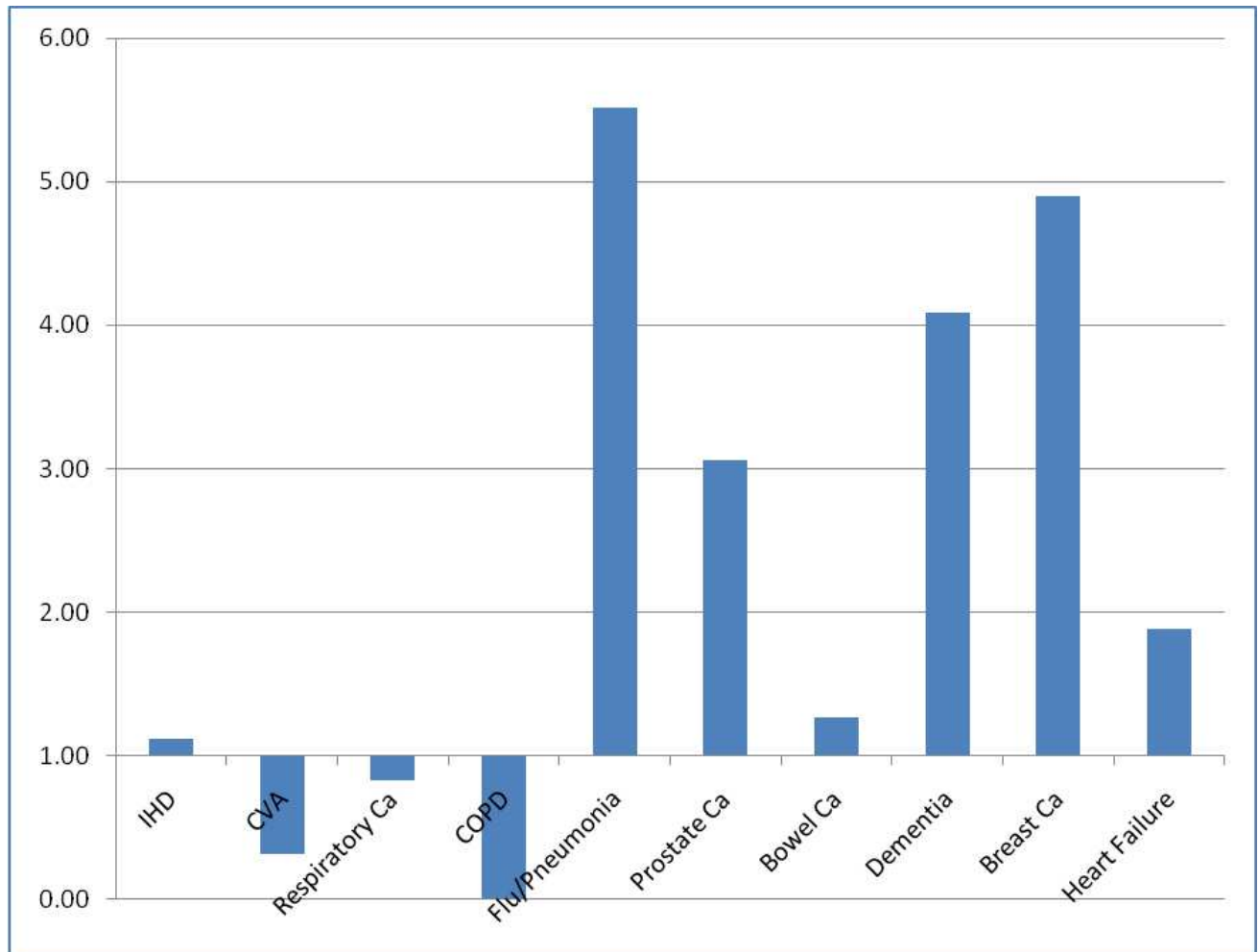

The relevant prevalence of disease in the media compared with actual incidence $78 \times 60 \mathrm{~mm}(300 \times 300 \mathrm{DPI})$ 